\title{
Experimental Study of 1.55-m EML-Based Optical IM/DD PAM-4/8 Short Reach Systems
}

Pang, Xiaodan; Ozolins, Oskars; Gaiarin, Simone; Kakkar, Aditya; Rodrigo Navarro, Jaime; Iglesias Olmedo, Miguel; Schatz, Richard; Udalcovs, Aleksejs; Westergren, Urban; Zibar, Darko

Total number of authors:

12

Published in:

IEEE Photonics Technology Letters

Link to article, DOI:

10.1109/LPT.2017.2662948

Publication date:

2017

Document Version

Peer reviewed version

Link back to DTU Orbit

Citation (APA):

Pang, X., Ozolins, O., Gaiarin, S., Kakkar, A., Rodrigo Navarro, J., Iglesias Olmedo, M., Schatz, R., Udalcovs, A., Westergren, U., Zibar, D., Popov, S., \& Jacobsen, G. (2017). Experimental Study of 1.55-m EML-Based Optical IM/DD PAM-4/8 Short Reach Systems. IEEE Photonics Technology Letters, 29(6), 523-6.

https://doi.org/10.1109/LPT.2017.2662948

\section{General rights}

Copyright and moral rights for the publications made accessible in the public portal are retained by the authors and/or other copyright owners and it is a condition of accessing publications that users recognise and abide by the legal requirements associated with these rights.

- Users may download and print one copy of any publication from the public portal for the purpose of private study or research.

- You may not further distribute the material or use it for any profit-making activity or commercial gain

- You may freely distribute the URL identifying the publication in the public portal 


\title{
$100 \mathrm{GHz}$ Externally Modulated Laser for Optical Interconnects
}

\author{
Oskars Ozolins, Member, IEEE, Xiaodan Pang, Member, IEEE, Miguel Iglesias Olmedo, \\ Aditya Kakkar, Aleksejs Udalcovs, Simone Gaiarin, Jaime Rodrigo Navarro, Klaus M. Engenhardt, \\ Tadeusz Asyngier, Richard Schatz, Jie Li, Fredrik Nordwall, Urban Westergren, Darko Zibar, \\ Sergei Popov, and Gunnar Jacobsen
}

\begin{abstract}
We report on a 116 Gbps on-off keying (OOK), 4 pulse amplitude modulation (PAM) and 105 Gbps 8PAM optical transmitter using an InP-based integrated and packaged externally modulated laser for high speed optical interconnects with up to $30 \mathrm{~dB}$ static extinction ratio and over $100 \mathrm{GHz} 3 \mathrm{~dB}$ bandwidth with $2 \mathrm{~dB}$ ripple. In addition, we study the trade-off between power penalty and equalizer length to foresee transmission distances with standard single mode fiber.
\end{abstract}

Index Terms-distributed feedback laser (DFB), direct detection, electroabsorption modulator, optical interconnects.

\section{INTRODUCTION}

$\mathrm{T}$ he third generation $400 \mathrm{Gbps}$ client-side links are demanding a solution as the cloud services together with the huge size datasets are driving demand for bandwidth in datacenters [1],[2]. Potential solutions are under discussion within the IEEE P802.3bs 400 Gigabit Ethernet (GbE) Task Force [3]. One attractive solution is based on eight optical lanes (i.e., $8 \times 50 \mathrm{Gbps} / \lambda$ [4]) thanks to compatibility with existing building blocks for $100 \mathrm{GbE}$ (drivers, lasers, and photodetectors with transimpedance amplifiers). However, large lane count increases complexity and power consumption resulting in higher costs [1]. More scalable and cost efficient approach is to reduce number of lanes and increase the bandwidth for a single lane. Four optical lanes at $100 \mathrm{Gbps}$ net rate (i.e., $4 \times 100 \mathrm{Gbps} / \lambda[5]$ ) are a promising solution in order to reduce complexity, power consumption and costs.

Manuscript received ; revised ; accepted

Date of publication ...........; date of current version ..................... This work is supported by EU projects ICONE gr. \#608099 and GRIFFON gr. \# 324391, Swedish ICT-TNG program and Vetenskapsrädet project PHASE (grant no. 2016-04510). The equipment was funded by Knut and Alice Wallenberg foundation. The Tektronix is acknowledged for equipment loan.

O. Ozolins, X. Pang, A. Udalcovs, J. Rodrigo Navarro, J. Li, G. Jacobsen is with the Networking and Transmission Laboratory, Acreo Swedish ICT AB, SE- 16425 Kista, Sweden (e-mail: oskars.ozolins@acreo.se).

M. Iglesias Olmedo, A. Kakkar, R. Schatz, U. Westergren, S. Popov is with the School of ICT, KTH Royal Institute of Technology, Electrum 229, Kista, SE-164 40, Sweden.

S. Gaiarin, D. Zibar is with the DTU Fotonik, Technical University of Denmark (DTU), Kongens Lyngby, 2800, Denmark.

K. M. Engenhardt, T. Asyngier is with the Tektronix GmbH, Stuttgart, Germany.

F. Nordwall is with the Tektronix AB, Stockholm, Sweden.
However, this task becomes even more challenging since it requires silicon and InP opto-electronic components with more than $70 \mathrm{GHz}$ bandwidth.

Advanced modulations formats are extensively studied for short reach applications: (1) pulse amplitude modulation (PAM) [6]-[16], (2) carrierless amplitude phase (CAP) modulation [17], or (3) discrete multi-tone (DMT) [13],[18]. Such formats allow for more efficient bandwidth utilization at the cost of complex digital signal processing (DSP), which also may result in a higher costs and power consumption. These demonstrations usually require long digital filters resulting in complicated implementations. Hence, consensus seems to evolve towards 4PAM [6]-[16] and on-off keying (OOK) [14],[19]-[23] as it saves complexity on the transmitter side. Limiting amplifiers and electrical multiplexers technologies up to $120 \mathrm{Gbps}$ have already matured into products. However, cost-efficient optical modulators at this bandwidth are not commercially available yet. PAM may reduce the bandwidth requirements, but it also reduces the receiver sensitivity and significantly complicates the electrical side of the transmitter (i.e., digital to analogue converters (DACs), linear drivers etc.). Therefore, higher bandwidth optoelectronic components with simpler modulation formats seem to be the most practical.

In this paper, we report on a cost-efficient integrated externally modulated laser (EML) with high bandwidth for 116 Gbps OOK (the first time achieved on a single EML [20] with low complexity DSP) and linear enough to accommodate 116 Gbps 4PAM and 105 Gbps 8PAM, while requiring a driving voltage of $2 \mathrm{Vpp}$, paving the way for high speed multilevel modulation formats.

This paper is organized as follows. Section II summarizes the related works and provides description of the externally modulated laser. In Section III, the experiment setup is detailed. The experimental results are shown and complemented with system simulations in Section IV. The conclusions are drawn in Section V.

\section{EXTERNALLY MODULATED LASER}

\section{A. Previous Experimental Demonstrations}

The optical transmitter is based on a monolithically integrated distributed feedback laser with traveling-wave electroabsorption modulator (DFB-TWEAM) designed by 

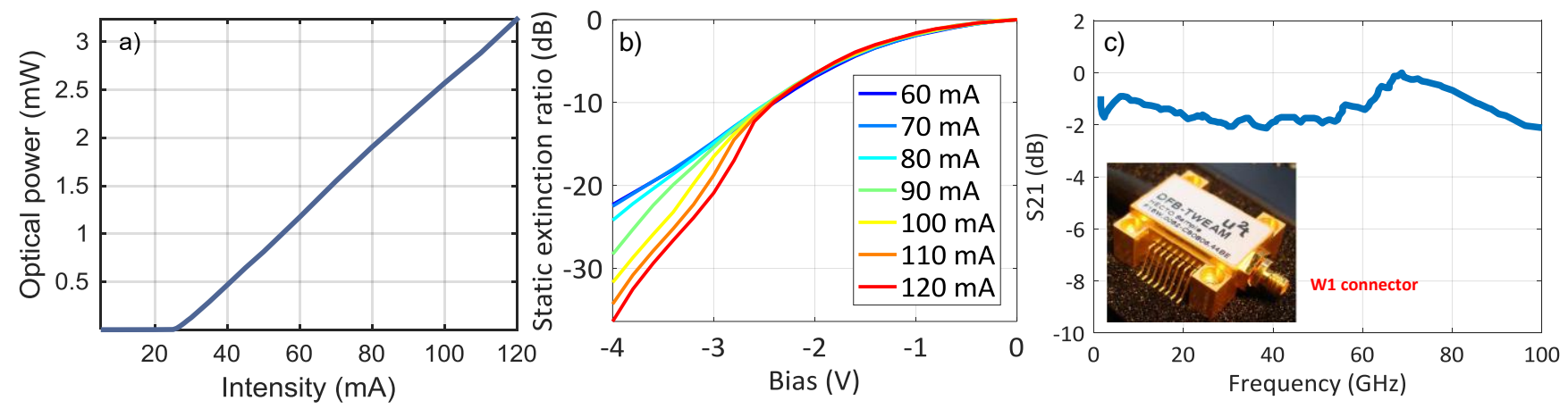

Fig. 1. a) $P(I)$ characteristics for unbiased modulator b) static extinction ratio characteristics c) $S 21$ characteristics as measured in [22].

KTH, fabricated by KTH and Syntune and packaged by $\mathrm{u}^{2} \mathrm{t}$ Photonics [22],[23]. In [23], the performance of already packaged DFB-TWEAM transmitter module for $100 \mathrm{Gbps}$ data rate is evaluated experimentally using 100 meters long standard single mode fiber (SSMF) and $10 \mathrm{~km}$ optical link with dispersion management. In [21] successful field trial is demonstrated with transmission of $112 \mathrm{Gbps}$ OOK signals using a purely electrical time division multiplexing-based system without DSP. A bit error rate (BER) performance below the forward error correction (FEC) threshold of $2 \cdot 10^{-3}$ is achieved after transmission over $42 \mathrm{~km}$ field installed SSMF with dispersion management between Kista and Råsunda in Sweden. It is the first demonstration of a complete $112 \mathrm{Gbps}$ ETDM system based on monolithically integrated transmitter [23] and receiver modules.

\section{B. Device Structure and Characterization}

The TWEAM is based on the 12 strain-compensated InGaAsP quantum wells/barriers (QWs) of around $9 \mathrm{~nm}$ thickness each. The total active length of modulator is $180 \mu \mathrm{m}$. The gain section of the DFB is based on 7 QWs $7 \mathrm{~nm}$ thick grown by metal vapour phase epitaxy coupled with buttjoint technique. The laser is $440 \mu \mathrm{m}$ long with a grating designed to have most of the output power towards the modulator. Components are formed in standard ridge waveguide structures [22]. Figure 1 shows the power versus current for unbiased modulator, power versus bias voltage and

a)

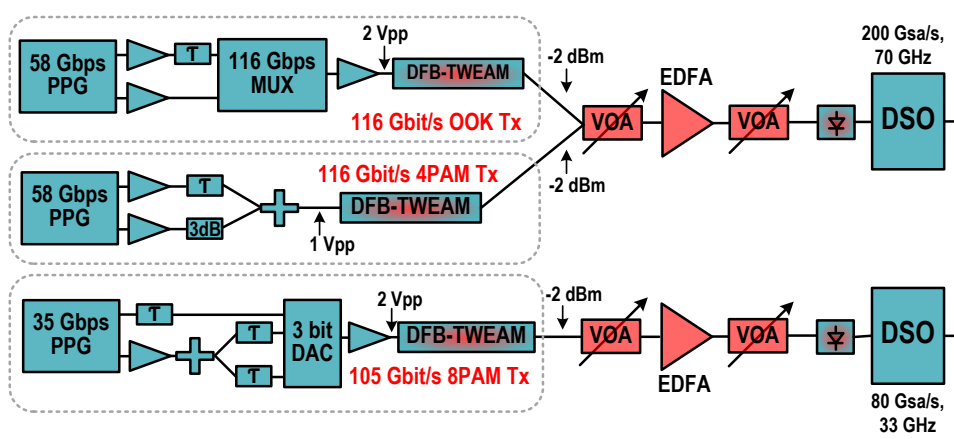

the frequency response taken at $22^{\circ} \mathrm{C}$ [24]. As we can see from Fig. 1a, the threshold current is $\sim 25 \mathrm{~mA}$, and the slope efficiency is $.04 \mathrm{~W} / \mathrm{A}$, which allows us to reach about $2 \mathrm{~mW}$ with only $80 \mathrm{~mA}$ driving current. Fig. 1b shows the static extinction ratio versus bias voltage. We can observe that the device has a static extinction ratio in the range of 20 to $35 \mathrm{~dB}$. The dynamic extinction ratio during modulation is related to modulator bias voltage and swing of driving voltage. The S21 curve of the device [22] (W1 connector) depicted in Fig. 1c clearly shows beyond $100 \mathrm{GHz} 3 \mathrm{~dB}$ bandwidth, the highest reported bandwidth to the best of our knowledge, with less than $2 \mathrm{~dB}$ ripple in the pass band of the EML [22] which indicates high phase linearity. These figures of merits [22] are order of magnitude better than state-of-art EMLs for optical interconnects.

\section{EXPERIMENTAL SETUP}

Figure 2 shows the transmitter setup for $116 \mathrm{Gbps}$ OOK, 4PAM and $105 \mathrm{Gbps}$ 8PAM with receiver setup including DSP (see Fig. 2a) and output optical spectrum of modulated signals (see Fig. 2b). In the OOK setup, two pseudo-random bit sequences with a word length of $2^{15}-1$ (PRBS15) at $58 \mathrm{Gbps}$ are first decorrelated and then multiplexed into a single $116 \mathrm{Gbps}$ sequence. A $110 \mathrm{GHz}$ traveling-wave limiting amplifier (TWA110 [25]) is used to drive the EML. In the 4PAM setup, two PRBS15 are first decorrelated and then

Fig. 2. a) Experimental setup. (PPG: pulse-pattern generator, Mux: Multiplexer, DAC: digital to analog converter T: Delay line, EDFA: erbium doped fiber amplifier, PD: Photodiode, DSO: digital storage oscilloscope, DSP: digital signal processing, LPF: low pass filter, FFE: Feed forward equalizer, DFE: decisionfeedback equalizer). b) Optical spectrum of the modulated signals (@0.01 nm resolution bandwidth). 


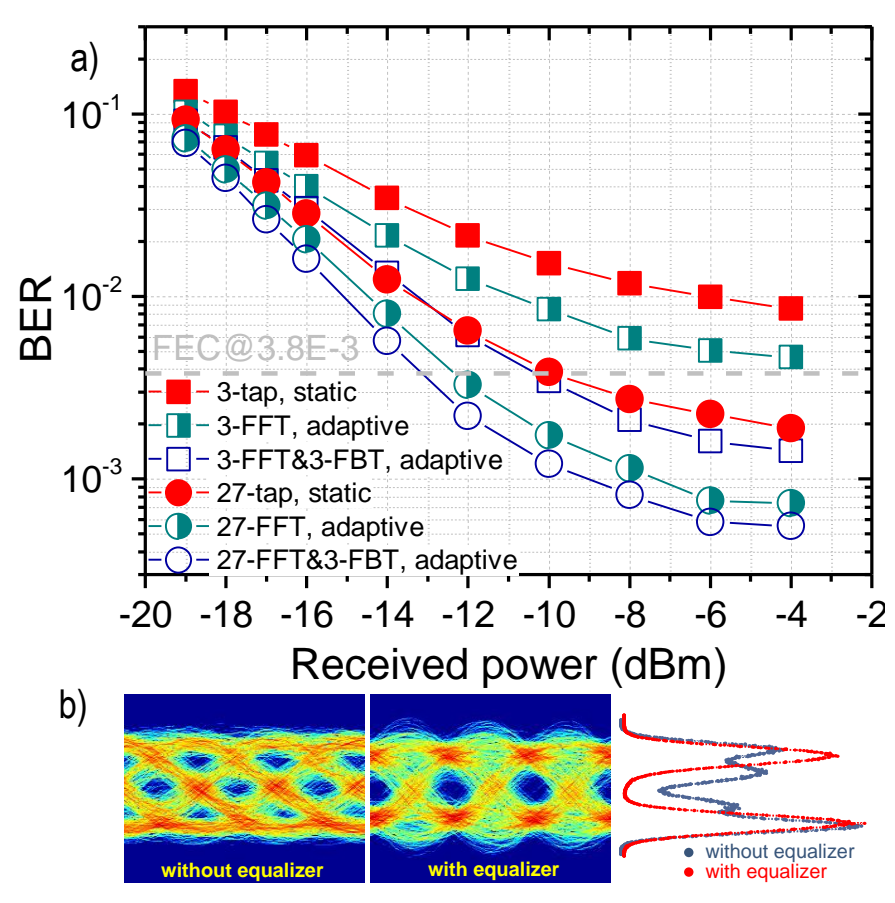

Fig. 3. a) BER curves for $116 \mathrm{Gbps}$ OOK. b) Received eye diagram without and with equalizer and histograms for $116 \mathrm{Gbps}$ OOK at $-2 \mathrm{dBm}$ input power.

passively combined into a 4PAM signal, which is then used to directly drive the EML. In the 8PAM setup, three PRBS15 sequences at $35 \mathrm{Gbps}$ are first decorrelated and then combined in a 3 bit DAC with $19 \mathrm{GHz}$ analogue bandwidth. A $65 \mathrm{GHz}$ linear amplifier is used to drive the EML. During measurements the bias voltage was kept at minus 2 volts and driving voltage was $2 \mathrm{Vpp}$ for OOK, 8PAM and $1 \mathrm{Vpp}$ for 4PAM. The average output power was kept at minus $2 \mathrm{dBm}$ in all cases. The receiver is composed of an Erbium doped fiber

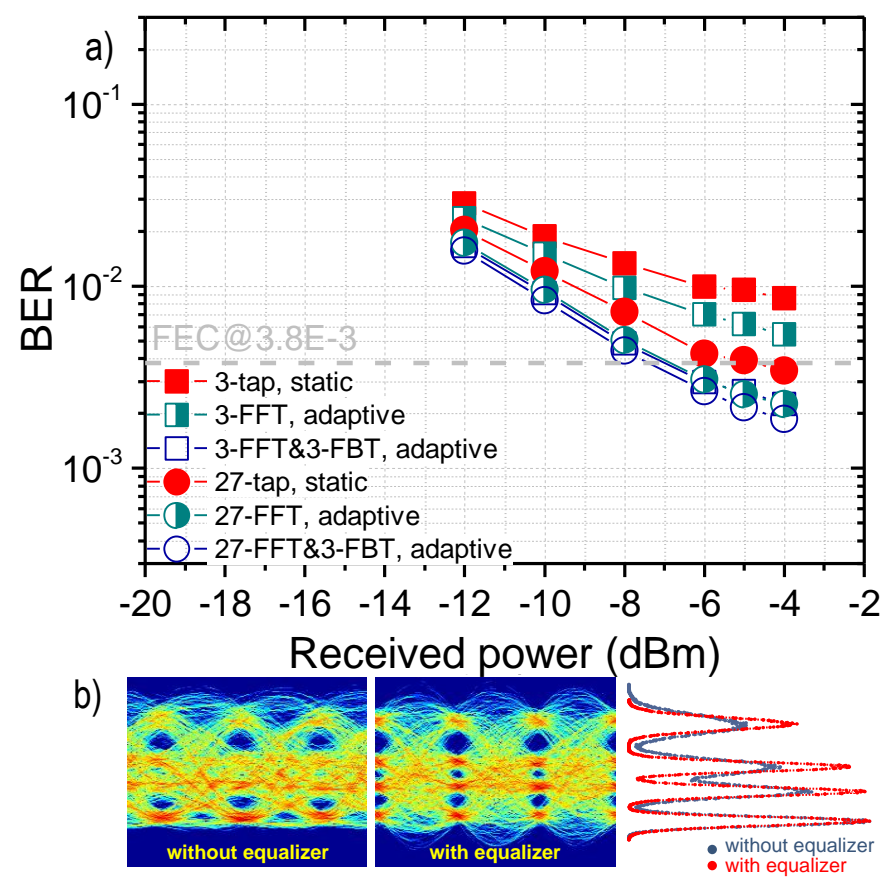

Fig. 4. a) BER curves for 116 Gbps 4PAM. b) Received eye diagram without and with equalizer and histograms for $116 \mathrm{Gbps} 4 \mathrm{PAM}$ at $-2 \mathrm{dBm}$ input power.

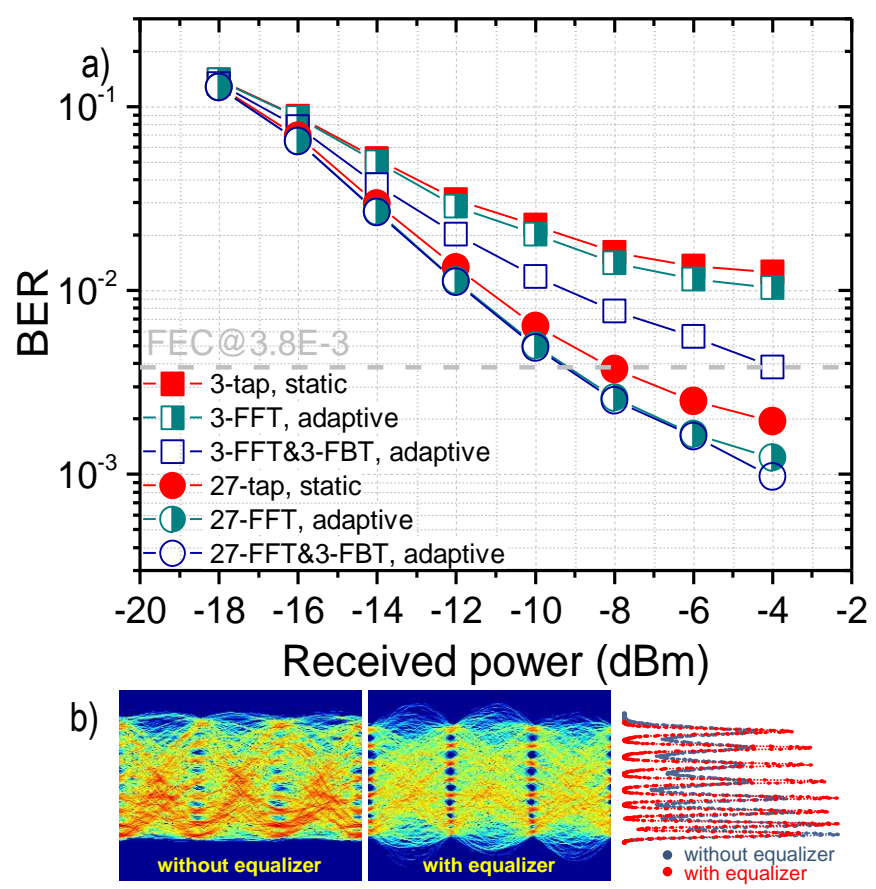

Fig. 5. a) BER curves for 105 Gbps 8 PAM. b) Received eye diagram without and with equalizer and histograms for $105 \mathrm{Gbps} 8 \mathrm{PAM}$ at $-2 \mathrm{dBm}$ input power.

amplifier (EDFA), variable optical attenuator (VOA), a high bandwidth photodiode (PD) from $\mathrm{u}^{2} \mathrm{t}$ with a responsivity of $0.5 \mathrm{~A} / \mathrm{W}$, and a $200 \mathrm{GSa} / \mathrm{s}, 70 \mathrm{GHz}$ bandwidth Tektronix digital sampling oscilloscope (DSO) (DPO77002SX) for OOK as well as 4PAM setups, while $80 \mathrm{GSa} / \mathrm{s}, 33 \mathrm{GHz}$ DSO - for 8PAM setup. An automatic gain-controlled EDFA with fixed output power is employed as a pre-amplifier due to the low PD responsivity and the lack of transimpedance amplifier. The sampled signal is then processed offline using DSP. The clock recovery and resampling is performed on the received waveform. The signal is then downsampled to 1 sample per symbol for static/adaptive feed forward equalizer (FFE) with different number of taps to overcome inter symbol interference (ISI) or symbol-spaced adaptive decisionfeedback equalizer (DFE) with different configuration of feedforward taps (FFT) and feedback taps (FBT) to overcome ISI in presence of noise. The initial weights of the equalizer were obtained using training data with the normalized least-meansquare (NLMS) algorithm before applying other data. A total number of 1.2 million bits are used for BER counting. The bandwidth limitation is due to limited effective $3 \mathrm{~dB}$ bandwidth on the transmitter side components used to generate electrical signals, while additional filtering occurs due to the limited DSO bandwidth, affecting the performance of OOK and 8PAM setups.

\section{RESUlTS AND DISCUSSIONS}

Obtained results provide the quantitative and qualitative performance evaluation of the optical transmitter for its capabilities to enable the third generation $400 \mathrm{Gbps}$ client-side links for optical interconnects. Figure 3 shows BER curves for $116 \mathrm{Gbps}$ OOK (see Fig. 3a) and the qualitative measure in 


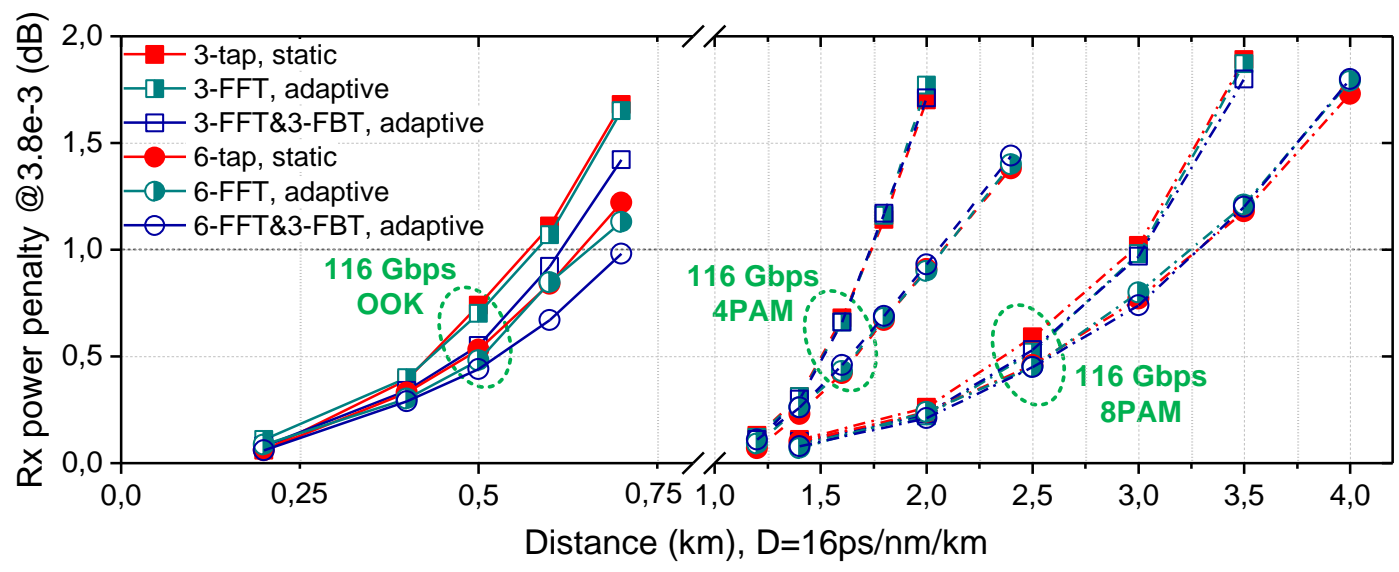

Fig. 6. Received power penalty as function of transmitted distance for $116 \mathrm{Gbps}$ OOK, 4PAM and 8PAM for different equalizer configurations (see inset).

terms of eye diagram and the histogram distribution of the received signal (see Fig. 3b). BER curves are obtained using 3-tap and 27-tap static filter, 3-FFT and 27-FFT adaptive FFE, and 3-FFT\&3-FBT and 27-FFT\&3-FBT DFE. One can observe that the use of 3-FFT\&3-FBT DFE allows achieving below 7\% FEC limit performance, which was further improved with larger lengths of equalizers. Adding small feedback in equalizer allows significantly improving the performance. We also observed that 27-tap static filter allows achieving almost the same performance as 3-FFT\&3-FBT DFE. Performance is further improved by $3 \mathrm{~dB}$ (reduction in power penalty) with 27-FFT\&3-FBT DFE. Figure 3b shows the received eye diagrams and histograms with and without equalizer for $116 \mathrm{Gbps}$ OOK signal. We can see that the signal is limited by both ISI and noise. The histogram without equalizer shows level degeneration owing to the ISI which we also observed in the electrical signal.

Figure 4 shows BER curves (see Fig. 4a), eye diagrams and histograms (see Fig. 4b) before and after equalizer for $116 \mathrm{Gbps}$ 4PAM. BER curves are obtained using same equalizers as in OOK case. We can see large degradation on the 4PAM signal owing to both higher sensitivity requirements and poor electrical signal performance at the transmitter. After equalizer one can observe that passive combining ratio is suboptimal (see transmitter design in Fig. 2a), which explains the worse performance. We use the EML to compensate this effect by driving it at high reverse bias voltage ( -2 volts). We are able to improve the performance, however, this causes compression on the upper levels and thus a trade-off was found. By adding 3-FFT\&3FBT DFE, a BER below FEC limit was achieved. We did not observe significant improvement by increasing the length of equalizer.

Figure 5 shows BER curves for 105 Gbps 8PAM (see Fig. 5a) and eye diagram and the histogram distribution of the received signal (see Fig. 5b). Similarly to previous cases BER curves are obtained using same configuration as before. Sensitivity for 8PAM is lower than 4PAM, but thanks to the performance of the 3 bit DAC, the implementation penalty is lower. However, still some compression is observed. One can observe that the performance of 3-FFT\&3-FBT DFE is below the 7\% FEC limit. Still performance can be significantly improved (reduction in power penalty is $4 \mathrm{~dB}$ with 27 -tap static filter and $5 \mathrm{~dB}$ with 27-FFT\&3-FBT DFE) with increased length of equalizer since the main bandwidth limitation is the $19 \mathrm{GHz}$ bandwidth of the DAC. Therefore, by ensuring sufficient bandwidth in the electrical domain, the optical transmitter has the potential of transmitting >100 Gbaud signals with low DSP requirements.

Operational wavelength of the EML is around $1548 \mathrm{~nm}$ in these measurements. To complement the experiments we study chromatic dispersion tolerance for different modulation formats using Monte Carlo simulations. In simulation we assumed that all modulation formats are operated at $116 \mathrm{Gbps}$ for a fair comparison. In simulations we focus on tolerance to chromatic dispersion $(16 \mathrm{ps} / \mathrm{nm} / \mathrm{km})$. Only bandwidth limitation is PD with responsivity of $0.5 \mathrm{~A} / \mathrm{W}$ and $80 \mathrm{GHz}$ bandwidth. Received power penalty as function of transmitted distance is shown in Fig.6. We obtain curves for 3-tap and 6tap static filter, 3-FFT and 6-FFT adaptive FFE, and 3FFT\&3-FBT and 6-FFT\&3-FBT DFE. For $1 \mathrm{~dB}$ power penalty, the $116 \mathrm{Gbps}$ OOK format can be transmitted up to 700 meters using 3-FFT\&3-FBT DFE. The distance for 116 Gbps 4PAM can be increased about three times compared to OOK for same penalty and equalizer parameters. In case of $116 \mathrm{Gbps} 8 \mathrm{PAM}$, the dispersion penalty will be below $1 \mathrm{~dB}$ at $3 \mathrm{~km}$ distance using only a 3 -tap static filter.

We point out that the microwave design of the transmitter can be applied to a semiconductor material with larger bandgap in order to achieve modulation at another operation wavelength [23]. Then transmission distances over SSMF can be significantly improved.

\section{CONCLUSIONS}

We report on the performance of an EML with higher than $100 \mathrm{GHz}$ bandwidth for optical interconnects. We experimentally validate its potential for fast optical interconnects by transmitting $116 \mathrm{Gbps}$ OOK, 4PAM and $105 \mathrm{Gbps} 8 \mathrm{PAM}$ signals. Furthermore, this is the first time [20] that 116 Gbps OOK is achieved on a single EML based 
optical transmitter with low complexity DSP. We study the trade-off between power penalty and equalizer length using Monte Carlo simulations. According to simulation results, a transmission of $3 \mathrm{~km}$ standard single mode fiber with less than $1 \mathrm{~dB}$ dispersion penalty using only 3-tap static filter for 116 Gbps 8PAM seems to be possible. We conclude that, provided sufficient bandwidth and linearity on the electrical domain, this optical transmitter can be used for advanced modulation formats at higher than 100 Gbaud.

\section{REFERENCES}

[1] M. Angel Mestre et al., "Compact InP-Based DFB-EAM Enabling PAM-4 112 Gb/s Transmission Over 2 km," J. Lightwave Technol., vol. 34, no. 7, p. 1572-1578, Apr., 2016.

[2] H. Mardoyan et al., "Single Carrier 168-Gbit/s Line-Rate PAM direct detection transmission using high-speed Selector Power DAC for Optical Interconnects," J. Lightwave Technol., vol. 34, no. 7, p. 15931598, Apr., 2016.

[3] IEEE P802.3bs $400 \mathrm{~Gb} / \mathrm{s}$ Ethernet Task Force. [Online]. Available: http://www.ieee802.org/3/bs/.

[4] F. Karinou et al., "Directly PAM-4 modulated 1530-nm VCSEL enabling $56 \mathrm{~Gb} / \mathrm{s} / \lambda$ data-center interconnects," IEEE Photon. Technol. Lett., vol. 27, no. 17, p. 1872-1875, Sep., 2015.

[5] X. Yin et al., "First Demonstration of Real-Time $100 \mathrm{Gbit} / \mathrm{s}$ 3-Level Duobinary Transmission for Optical Interconnects" in ECOC, Düsseldorf, 2016, postdeadline paper Th.3.B5.

[6] S. Kanazawa et al., "Transmission of 214-Gbit/s 4-PAM signal using an ultra-broadband lumped-electrode EADFB laser module," in $O F C$, Anaheim, CA, 2016, postdeadline paper Th5B.3.

[7] Y. Matsui et al., "55-GHz Bandwidth Short-Cavity Distributed Reflector Laser and its Application to 112-Gb/s PAM-4," in $O F C$, Anaheim, CA, 2016, postdeadline paper Th5B.4.

[8] K. Szczerba et al., "94 Gbps 4-PAM using an $850 \mathrm{~nm}$ VCSEL, preemphasis and receiver equalization," IEEE Photon. Technol. Lett., vol. 28, no. 22, p. 2519-2521, Nov., 2016.

[9] A. D. Simard, et al., "Segmented silicon MZM for PAM-8 transmissions at $114 \mathrm{~Gb} / \mathrm{s}$ with binary signaling," Opt. Express vol. 24, no. 17, p. 19467-19472, Aug., 2016.

[10] Q. Zhang et al., "Single-lane $180 \mathrm{Gbit} / \mathrm{s}$ PAM-4 signal transmission over $2 \mathrm{~km}$ SSMF for short-reach applications," Opt. Lett. vol. 41, no. 19, pp. 4449-4452, Oct., 2016.

[11] X. Pang et al., "Evaluation of High-Speed EML-based IM/DD links with PAM Modulations and Low-Complexity Equalization," in ECOC, Düsseldorf, 2016, paper W.4.P1.SC5.54

[12] S. Gaiarin et al., "High Speed PAM-8 Optical Interconnects with Digital Equalization based on Neural Network," in ACP, Wuhan, 2016, paper AS1C.1.

[13] R. Lin et al., "Performance Evaluation of PAM and DMT for Shortrange Optical Transmission with High Speed InGaAsP DFB-TWEAM," in $O F C$, Anaheim, CA, 2016, paper Th2A.58.

[14] S. Lange et al., "Low Switching Voltage Mach-Zehnder Modulator Monolithically Integrated with DFB Laser for Data Transmission up to 107.4 Gb/s," J. Lightwave Technol., vol. 34, no. 2, p. 401-406, Jan., 2016.

[15] K. Zhong et al., "140-Gb/s 20-km Transmission of PAM-4 Signal at 1.3 $\mu \mathrm{m}$ for Short Reach Communications," IEEE Photon. Technol. Lett., vol. 27, no. 16, p. 1757-1760, Aug., 2016

[16] A. D. Simard et al., "Segmented silicon MZM for PAM-8 transmissions at $114 \mathrm{~Gb} / \mathrm{s}$ with binary signaling," Opt. Express., vol. 24, no. 17, p. 19467-19472, Oct., 2016

[17] M. Iglesias Olmedo et al., "Multiband Carrierless Amplitude Phase Modulation for High Capacity Optical Data Links," J. Lightwave Technol., vol. 32, no. 4, p. 798-804, Feb., 2014.

[18] H. Yamazaki et al., "300-Gbps Discrete Multi-tone Transmission Using Digital-Preprocessed Analog-Multiplexed DAC with Halved Clock Frequency and Suppressed Image" in ECOC, Düsseldorf, 2016, postdeadline paper Th.3.B4

[19] K. Zhong et al., "Transmission of a 120-GBd PM-NRZ Signal Using a Monolithic Double-Side EML," IEEE Photon. Technol. Lett., vol. 28, no. 20, p. 2176-2179, Oct., 2016
[20] O. Ozolins et al., "100 GHz EML for High Speed Optical Interconnect Applications," in ECOC, Düsseldorf, 2016, upgraded invited paper M2.4.4.

[21] J. Li et al., " $112 \mathrm{~Gb} / \mathrm{s}$ field trial of complete ETDM system based on monolithically integrated transmitter \& receiver modules for use in $100 \mathrm{GbE}$," in ECOC, Torino, 2010, paper P4.03.

[22] M. Chacinski et al., "Monolithically Integrated $100 \mathrm{GHz}$ DFBTWEAM," J. Lightwave Technol., vol. 27, no. 16, p. 3410-3415, Aug., (2009).

[23] M. Chacinski et al., "ETDM transmitter module for 100-Gb/s Ethernet," IEEE Photon. Technol. Lett., vol. 22, no. 2, p. 70-72, Jan., 2010.

[24] Y. Yu, et al., "Temperature-dependent effects in high-speed travellingwave electroabsorption modulators," Electron. Lett., vol. 41, no. 4, p. 209-211, Feb., 2005.

[25] V. Hurm et al., "InP DHBT-based modulator driver module for 100 Gbit/s Ethernet applications," Electron. Lett., vol. 45, no. 24, p. 12641266, Nov., 2009

Oskars Ozolins (M'09) received M.Sc. degree in Telecommunications from Riga Technical University, Riga, Latvia, in 2009 and the Dr.sc.ing $(\mathrm{PhD})$ degree in Optical Communications from Riga Technical University, in 2013. Since 2014 he has been working at Acreo Swedish ICT AB where currently he is research scientist under Vetenskapsrädet project PHASE. He also has been visiting researcher in DTU Fotonik, Technical University of Denmark, FOTON Laboratory (CNRS UMR 6082), ENSSAT, University of Rennes 1 , and Gent University. His research interests are in the areas of fiber-optic communications, photonic-wireless systems, optical signal processing, and high speed short-range transmission. He is the author or co-author of around 60 international publications, conference contributions, and book chapters. He holds one patent. He has regularly served as a designated reviewer for OSA Journals: Chinese Optics Letters, Applied Optics, Optics Express, and Photonics Research.

Xiaodan Pang (M'12) received M.Sc. degree in Photonics from KTH Royal Institute of Technology, Stockholm, Sweden, in 2010 and the Ph.D. degree in Optical Communications from DTU Fotonik, Technical University of Denmark, in 2013. Since 2013 he has been working with Acreo Swedish ICT as a postdoctoral researcher. His research interests are in the areas of fiber-optic communications, hybrid optical fiber-wireless technologies, $\mathrm{mm}$-wave and $\mathrm{THz}$ communications and ultrahigh speed short-range transmission technologies.

Miguel Iglesias Olmedo, biography not available at the time of publication.

Aditya Kakkar received B.Tech. in Electronics Engineering from Indian Institute of Technology (B.H.U), Varanasi, India in 2011 and double M. Sc. degrees in Electrical Engineering and Information Technology from KTH, Royal Institute of Technology, Stockholm Sweden and Karlsruhe Institute of Technology, Karlsruhe, Germany respectively in 2013. He 
worked as Assistant Manager (Optical Systems and Networks Research) at Sterlite Technologies Ltd., India from August, 2013 to June, 2014. He joined KTH/Acreo High Speed Transmission Lab as EU Marie Curie Early Stage Researcher in August, 2014 where he is currently pursuing his $\mathrm{PhD}$ in coherent optical communications.

Aleksejs Udalcovs received the degree of Doctor of Engineering Science (Dr.sc.ing.) in Optical Communications from the Riga Technical University (RTU), Riga, Latvia, in 2015. From 2012 to 2016, he was working as a visiting researcher and then as a postdoctoral researcher at the School of Information and Communication Technology (ICT), Royal Institute of Technology (KTH), Kista, Sweden. In mid-2015, he joined the KTH/Acreo High Speed Transmission Lab. Since the end of 2016, he is a postdoctoral researcher at the Networking and Transmission Laboratory (NETLAB) of Acreo Swedish ICT AB within Swedish ICT-The Next Generation (TNG) project.

Simone Gaiarin, biography not available at the time of publication.

Jaime Rodrigo Navarro received the M. Sc. degree in Telecommunications Engineering from the Universitat Politècnica de València, Valencia, Spain in 2014. He joined KTH/Acreo High Speed Transmission Lab as EU Marie Curie Early Stage Researcher in August, 2014 where he is currently pursuing his $\mathrm{PhD}$ in coherent optical communications.

Klaus M. Engenhardt, biography not available at the time of publication.

Tadeusz Asyngier, biography not available at the time of publication.

Richard Schatz was born 1963 and has since 1987 conducted research at the Laboratory of Photonics and Microwave Engineering at Royal Institute of Technology (KTH), Stockholm where he received his $\mathrm{Ph}$. D. degree in photonics in 1995 and works since then as senior researcher and lecturer. He spent 1992-1993 as a Visiting Scientist at AT\&T Bell Laboratories, Murray Hill, NJ. His research is mainly focused on modeling, design and characterization of fiber-optical transmitters (edge emitter lasers, VCSELs and modulators) and links, both for on-off keying and more advanced modulation formats. He has developed laser simulation software for the photonics industry and authored or coauthored more than 150 journal papers and conference contributions.

Jie Li, biography not available at the time of publication.

Fredrik Nordwall, biography not available at the time of publication.

Urban Westergren received the $\mathrm{MSc}, \mathrm{PhD}$ and Docent degrees from KTH Royal Institute of Technology in 1984, 1992 and 2002, respectively. From 1984 to 1993 he was a research engineer in high-speed electronics at the Swedish Institute of Microelectronics (IM) in Kista, Sweden. In 1994 he joined the Laboratory of Photonics and Microwave Engineering at KTH as a research associate. In 1996 he became associate professor, and in 2012 he was appointed full professor in the subject Optoelectronic Integrated Circuits at KTH. In the period 2000-2003 he was senior expert in electronic design at the company Optillion. He has been the teacher and examiner of over 1000 bachelor and master level students, and over $100 \mathrm{PhD}$ students, in courses in electromagnetics, microwave engineering, photonics and highspeed electronics. Since 2012 he is deputy director of international affairs with China at KTH regarding education. The research at KTH has included design and measurement of integrated receivers and transmitters for fiber optical communication at very high bitrates. During later years the research has focused on design of electroabsorption modulators for use in transmitters for speeds from 100 to $160 \mathrm{~Gb} / \mathrm{s}$. He was the main applicant for, and the coordinator of, the EU project HECTO throughout the project duration 2006-2010. HECTO was concluded with world-record field trials of a complete fiber optical communication system with $112 \mathrm{Gbit} / \mathrm{s}$ serial transmission using On-Off Keying over $42 \mathrm{~km}$. He is the author or co-author of around 100 international publications, conference contributions, and book chapters. He holds two patents.

Darko Zibar, biography not available at the time of publication.

Sergei Popov, biography not available at the time of publication.

Gunnar Jacobsen. Professor Jacobsen is educated at the Technical University of Denmark (DTU). He received his PhD in 1981 and was in 1988 awarded the Dr. techn. degree from DTU. From 1981 to 1997 he was a Senior Scientist working at 
the Danish Telecom Research Lab. From 1997 to 2002 he was working at Ericsson Research Lab from 2000 as the Research Lab Manager. From 2002 he has been working at the Swedish Research Institute Acreo AB in Kista. He is today a Professor in Optical Communication Systems at the Royal Institute of Technology (Swedish abbreviation KTH), Kista, Sweden as well as Deputy Department Head, Transmission and Networking Department/Netlab at ACREO AB. Professor Jacobsen has been active in research concerning high capacity optical transmission systems since 1976, currently focusing on coherent optical transmission systems where he is managing a joint KTH/Acreo research group. He has published more than
275 papers, one monograph and several book chapters in the area and holds three patents. He has supervised more than 35 $\mathrm{PhD}$ students. He has regularly served as a reviewer for Journals like Optics Express, IET Electronics Letters, IET Photonics \& Electro-Optics, IEEE Photonics Technology Letters, IEEE/OSA Journal of Lightwave Technology, IEEE Transactions on Communications, IEEE Transactions on Information Theory, Journal of Optical Communications. He has reviewed candidates for Professor Appointments at universities in the US and in Europe. 